\title{
Entre o coco e a ópera: cultura popular e ópera lírica na dramaturgia de Mario de Andrade
}

\author{
Between coco and opera: popular culture and lyrical \\ opera in the dramaturgy of Mario de Andrade
}

André Carrico ${ }^{1}$ 


\section{Resumo}

Mário de Andrade foi um escritor e animador cultural de múltiplos interesses. Sua obra artística é indissociável de seu pensamento crítico e propõe uma leitura do Brasil. A partir da análise dramatúrgica de sua ópera Café e da correlação do texto com parte dos relatos etnográficos compilados em $O$ Turista Aprendiz, pretendemos entender como a música de matriz popular e o coco, especialmente, serviram como elemento-chave da sua tentativa de renovação da linguagem da dramaturgia operística.

Palavras-chave: Dramaturgia: cultural popular: ópera; Mário de Andrade

\section{Abstract}

Mário de Andrade was a writer and entertainer with multiple interests. His artistic work is inseparable from his critical thinking and proposes a point of view of the Brazil. Through the dramaturgical analysis of his opera Café and the correlation of the text with part of the ethnographic accounts compiled in $O$ Turista Aprendiz, we intend to understand how the popular root's music and the coco especially served as a key element of his attempt to renew the language of operatic dramaturgy.

Keywords: Dramaturgy: popular culture: opera; Mario de Andrade 
Mário de Andrade (1893-1945) foi escritor, professor, poeta, ensaísta, musicólogo, etnógrafo, compositor, gestor e animador cultural, além de ter exercido outras funções daí decorrentes. É conhecido por inúmeros feitos culturais, na área da criação artística e da pesquisa, de ampla envergadura. A Semana de Arte Moderna de 1922 foi um deles. Toda a sua atividade e os produtos dela decorrentes direcionaram-se para dois eixos: a ruptura radical com as estéticas cristalizadas pela acomodação do academicismo e a construção de uma cultura fundada nas matrizes nativas.

A tudo o que fez, o escritor devotou rigor e profundidade. Integrou uma geração de espírito fundante: queria, com seus parceiros, inventar um projeto de Brasil. Ou, talvez, tenham mesmo inaugurado um Brasil, ou um novo olhar sobre o país. Sua obra crítica e artística é tão indissociável quanto coerente e está vinculada diretamente a esse olhar.

Como dramaturgo, Mário escreveu dois dramas poéticos (Eva e Moral Cotidiana) e duas óperas, Pedro Malazarte e Café, sendo a segunda inconclusa. A partir da análise dramatúrgica de Café e da correlação do texto com a crítica musical do autor e parte dos relatos etnográficos compilados em $O$ Turista Aprendiz, nossa pesquisa pretende entender como a música de matriz popular e o coco, especialmente, serviram como elemento-chave da sua tentativa de renovação da linguagem da dramaturgia operística.

Para além da Literatura, a dança e a música ocuparam grande parte dos múltiplos interesses de Mário de Andrade. Quando terminou seu curso de piano no Conservatório Dramático Musical de São Paulo, em 1918, o escritor paulistano já era professor de História da Música e Estética da mesma instituição. E foi nesse contexto que escreveu críticas à temporada lírica paulistana para o jornal A Gazeta em 1918-19 e em 1928 para o Diário Nacional. ${ }^{2}$ Uma de suas principais queixas em seus textos acerca da audiência de óperas no Theatro Municipal de São Paulo e no Theatro São Pedro era a mimetização das óperas europeias, principalmente as italianas. Sobretudo no segundo conjunto de críticas, de fins dos anos 1920, defende a importância de se criar uma ópera "brasileira", que traduza em linguagem cênico-musical os modos de ser, de pensar e de sentir da nossa gente - tal como vinham fazendo os poetas e romancistas na Literatura.

Segundo Sato (2014), as críticas de 1928 enfatizam mais a organização das temporadas líricas do que detalhes acerca das características estéticas ou a análise das performances das récitas. Em que pese as diferenças de enfoque dos dois conjuntos de críticas, em ambos parecem se fazer presentes o apelo à uma renovação da linguagem dramática e a busca por uma expressão artística nacional. Esses argumentos também são defendidos em sua obra Ensaio Sobre Música Brasileira, publicada no mesmo ano. Mário não queria mais acompanhar a fortuna de divas tuberculosas morrendo de paixão, melancólicos pierrôs lamentando seus destinos ou arlequins sevilhanos correndo a atender solicitações de seus amos. Desejava ouvir os cantos das lavadeiras, os pregões dos feirantes, as canções de ninar das babás negras, 0 reclamo dos estivadores explorados. Daí o seu interesse em criar uma "ópera brasileira" fazendo jus à reivindicação de sua crítica jornalística.

2 Parte desses artigos foi publicada pelo próprio Mário em livro em 1933, mesmo ano em que começou a escrever Café. Cf. Mário Andrade. Música, Doce Música, 1963. 
Sua primeira incursão pelo teatro lírico se deu em 1928, ao escrever o divertimento musical Pedro Malazarte. Nessa peça, musicada por Camargo Guarnieri, já aplica suas ideias nacionalistas, exigindo do compositor, a partir de suas rubricas, a intercorrência de melodias inspiradas nas formas da modinha, da ciranda, da embolada e do coco.

Mas sua principal obra para o teatro musical foi Café, iniciada em 1933 e sucessivamente reescrita até 1942. Ela foi pensada inicialmente como um "Romance de oitocentas páginas cheias de psicologia e intensa vida".

\begin{abstract}
Mário deixou várias versões de sua ópera coral concluída em 1942. Em 1939, vivendo no Rio de Janeiro, julgou ter encontrado o parceiro que buscava no amigo e compositor Francisco Mignone, a quem encomendou a partitura. O projeto da parceria, contudo, não chegou a se completar. Mário dedicou o manuscrito de Café, dividido em duas partes - "Concepção Melodramática" e "Tragédia Secular" (o poema) - a Liddy Chiafarelli, esposa de Mignone. Sua publicação ocorreu apenas em 1955, dez anos após a morte de Mário. (Levin, 2012, p.42)
\end{abstract}

Há relatos de que Mignone desistiu da tarefa de musicar o libreto devido à interferência relutante de Mário em seu trabalho (Toni, 2004). A única versão completa do texto, denominado "tragédia-coral", grifa as datas de 1935, 1939 e 1942 como três momentos de composição. ${ }^{3}$ Ao longo do tempo, houve ainda outras tentativas de musicalização da ópera, nas versões dos compositores Claudio Santoro (1953) e Marcos Nobre (1983). Mas foi Hans-Joachim Koellreutter o primeiro a conseguir finalizar uma proposta musical completa para a obra, em 1986, que só foi encenada em Santos, SP, em 1996.

Artista experimental - antes que essa definição existisse, Mário se lançou, nessa empreitada, na difícil tarefa de aliar uma estrutura dramatúrgica engessada por séculos de tradição - a ópera lírica, às poéticas rapsódicas das expressões dramáticas brasileiras. Buscou conjugar sua erudição de ouvinte (e ex-crítico) de óperas europeias à sua curiosidade de etnomusicólogo amador.

A peça é uma crítica ao primitivismo do capitalismo brasileiro. Narrativa alegórica e otimista sobre o processo revolucionário, Café trata da tragédia social que a crise do grão em 1929 gerou entre os trabalhadores. Insatisfeitos e acometidos pela carestia, estivadores, colonos, operários, suas mulheres e famílias se rebelam contra patrões e políticos e agitam uma revolta. Ao final, após invadirem um cortiço, triunfa o "dia novo" numa apoteose calma anunciada pela Mãe. "O canto de encerramento, marcado pela reiteração do café como fonte de vida, força de paz e justiça social, transmite a mensagem profética da libertação possível com o engajamento político" (Levin, 2012, p.42)

As produções de Mário de Andrade no gênero dramático, incluindo aí Eva (1919) e Moral Cotidiana (1922) são experiências no gênero oratório e aproximam-se, no máximo, ao que se pode denominar de "poesia dialogada" ou "drama poético". Como teatro estritamente falado, nada escreveu. O que teria levado o poeta, já razoavelmente prestigiado àquela altura, a arriscar seu nome e a dedicar tanto de seu tempo e talento a esse gênero? Não poderia ter se voltado à criação de peças teatrais (faladas)? Para

3 Esta pesquisa utilizou como referência a versão completa e anotada de Café, estabelecida por Flávia Camargo Toni. Café, uma ópera de Mário de Andrade: estudo e edição anotada. São Paulo, 2004. 
prejuízo da dramaturgia brasileira, talvez o apreço do autor pelo teatro restringia-se ao drama cantado e bailado, não falado.

Em relação à finalidade do espetáculo lírico, para Mário, "Cumpria resgatar, segundo ele, o sentido popular que havia se desviado de sua função principal no serviço aos interesses de uma classe minoritária" (Levin, 2012, p. 40). O objetivo social de sua empreitada é claro, portanto. Ele pretendia "falar ao povo, como povo, voltar às raízes, desmascarar a ilustração, sem renegar a erudição" (Levin, 2012, p. 40). Estamos tratando de um intelectual engajado no afã das utopias político-sociais dos anos 1920/30.

Em Café encontramos os principais atributos do gênero operístico padrão: monumentalidade na descrição cenográfica, apelo histórico do tema, força trágica da ação dos personagens (quase todos coletivos), caráter nacionalista na premissa dramática.

Em relação aos elementos básicos da ópera clássica, cumpre destacar que, em comparação com o drama falado, uma de suas vantagens é expandir a intensidade dramática das situações a partir das cores que a música oferece à palavra, acrescentando ao concreto da poesia a potência abstrata dos sons.

Linguagem e música podem fazer, juntas, aquilo que nenhuma das duas pode fazer em separado. Esta combinação única cria, ao mesmo tempo, percepção dramática e beleza musical - um conhecimento imediato do personagem ou da situação, coisa que nenhuma outra forma de arte consegue. (Digaetani, 1988, p. 12)

Nesse aspecto, entretanto, o escritor ficaria à mercê de um compositor que alcançasse a potência poética de seus versos. Seu exercício arriscado dependia da harmonia na parceria com um músico sensível a seu escopo, perspicaz e competente; tão conhecedor da linguagem musical quanto Mario era da poética literária. Talvez, no entender de Mário, àquela altura, Mignone, pela ambição nacionalista de sua própria obra, estivesse à altura dessa tarefa.

Nas dramatis personae de Café, o herói tradicional da dramaturgia lírica é substituído pelos coletivos de explorados. Em lugar de pessoas, o que move a ação dramática são os coros: dos Fazendeiros, dos Colonos, das Famintas, dos Estivadores, das Operárias, dos Serventes, dos Rapazes, das Moças, dos Velhos, dos Revolucionários, dos Governistas. Como indivíduos, figuram apenas, em rápidas aparições, o Deputadinho e uma Mãe, num belo solo que se repete em duas cenas.

Quando principiou a escrever a ópera, Mário compartilhava do entusiasmo com a experiência socialista soviética. O libreto critica nossa elite mesquinha e ignorante. Substitui os personagens-sujeito pelos coros de trabalhadores, vítimas das condições históricas. Mário anunciava uma forte preocupação com o caráter social e libertário do teatro e no lugar dos cultuados solistas desejava ver conjuntos de personagens a cantar. Quem sabe, em sua produção imaginária, os estudantes de canto do Coral Lírico tomassem o protagonismo das prime donne ítalo-paulistas.

A ópera é vista não do ponto de vista de entretenimento burguês, mas pela força social do teatro cantado. Do ponto de vista conteudístico, ao moralismo edificante do melodrama, da tragédia e do verismo ainda preponderantes no repertório da época, Mário interpõe a dialética épica como instrumento de conscientização política.

$\mathrm{Na}$ sua dramaturgia, em paralelo ao ethos de panfleto revolucionário, coexiste o pathos representado no grão como signo de um espírito místico de morte e ressurreição. 
A mesma mística que talvez o tivesse arrebatado ao ouvir a voz do cantador de cocos Chico Antônio, na Fazenda Bom Jardim, no Rio Grande do Norte, em sua excursão a esse Estado em 1929.

O autor da Pauliceia queria denunciar o egoísmo e defender o coletivismo não apenas no conteúdo de seu texto, assim como na forma. O drama apresenta o colapso social instaurado naquele momento pelo ponto de vista da classe trabalhadora e, nesse aspecto, também é inovador. Poucas são as peças teatrais brasileiras produzidas até então nas quais os trabalhadores, além de protagonistas, fogem do estereótipo dos criados passivos e submissos para apresentarem um comportamento proativo. Esse comportamento está expresso no discurso crítico e nas iniciativas de rebeldia dos personagens-coletivos de Café.

Como vimos, a primeira versão da ópera é de 1933, mesmo ano de dois clássicos do teatro socialista-militante brasileiro: Deus lhe pague de Joracy de Camargo e $O$ Rei da Vela de Oswald de Andrade. ${ }^{4}$

É impossível não aproximá-la da peça Mistério-Bufo, escrita por Vladimir Maiakovski no calor da revolução bolchevique entre 1918 e 1921 . O mesmo tom futurista de exaltação à máquina e à velocidade, a brincadeira anárquica com sílabas, frases e valores da norma culta do idioma e o tom panfletário de crítica social estão presentes no libreto de Andrade. Não se trata aqui de saber se o autor paulista teve contato com alguma tradução da peça-musical russa - o que não diminui em nada o valor do texto de sua ópera. O importante é reconhecer que há muitos pontos de convergência, em tema e linguagem.

A velocidade e a simultaneidade da experiência de se viver numa metrópole, a dimensão estética da força que move o progresso são, na capital paulista, situações contemporâneas ao período de produção do texto. São também ingredientes de inspiração futurista utilizados pelo autor na sua primeira ópera. De resto, esse era o espírito da época: apresentar um novo homem para um novo mundo. A máquina capitalista avassaladora esmagava brutalmente a força de trabalho e a reação que desse ato pudesse advir poderia ser bela. Beleza a ser traduzida em palavras e sons. No último ato de Café, o canto coral de grupos de mulheres e revolucionários alterna-se, caoticamente, à voz de um parlatório no rádio e se mistura a troadas, bombas, gritos e alarmes, num crescendo rítmico que anuncia a chegada do combate.

A imagem posta em ação no drama de corpos e braços de lavradores e estivadores, sôfregos na batalha por seu ganha-pão, tal como numa tela de Portinari ${ }^{5}$, denuncia a situação de um Brasil pré-consolidação das leis do trabalho, semiescravocrata, esboçando um capitalismo que mal se pronunciou e já sucumbiu diante do capital estrangeiro.

Mário fazia parte de um grupo de pensadores dos anos 1920/30 que sonhava encontrar uma unidade cultural para o Brasil. A ordem do dia era parar de macaquear o que vinha de fora, olhar para o umbigo, apreciar sua beleza, valorizá-la. Era na Cul-

\footnotetext{
4 Em 1933 também foram escritos e encenados dois outros textos que, em diferentes direções, não sociais - mas formais, marcam rupturas na dramaturgia nacional: Amor de Oduvaldo Vianna e $O$ bailado do deus morto de Flávio de Carvalho.

50 próprio Mário cita a tela A Colona Sentada, que adquiriu de seu amigo de Brodowski em 1935, como sugestão de imagem na sinopse que introduz o texto da ópera. Parece que as imagens figurativas de Portinari ajudam o escritor a visualizar seus personagens. O pintor, aliás, foi premiado no mesmo ano (1935) com a Menção Honrosa da Exposição Internacional do Carnegie Institute de Pittsburg, Estados Unidos, por um quadro intitulado Café.
} 
tura Popular que se esconderia uma identidade a ser desvelada. A cultura construída ao longo dos séculos pelo povo; rural, anônima, coletiva, espontânea e oral, seria a portadora do autêntico "espírito" da nação.

Um dos objetivos do programa modernista foi investigar in loco um Brasil profundo, um Brasil das regionalidades, que não estava no mapa da cultura oficial. E foi na obra do autor de Macunaíma que esse objetivo se realizou mais plenamente. Daí as pesquisas de campo que realizou, a partir de 1921. Nelas coletou dados, canções, causos, pregões, parlendas, experiências afetivas, gustativas, olfativas, auditivas... fez registros fonográficos e fotográficos, anotou, refletiu, sentiu.

A ausência (voluntária, até certo ponto) de uma metodologia de pesquisa estabelecida por terceiros ${ }^{6}$ deu a Mário grande liberdade nos modos de selecionar e de tratar os dados recolhidos, estendendo seu olhar sempre curioso para múltiplos e díspares aspectos de cada lugar por onde passava. Desde as visitas ao interior paulista, sobretudo à fazenda de seu Tio Pio, em Araraquara, até a sua primeira expedição em companhia dos modernistas para o interior de Minas Gerais, em 1924, da qual surgiu o movimento Pau Brasil. A segunda "visita de campo" foi uma viagem em companhia de Dona Olivia Guedes Penteado à Região Norte do Brasil, em 1927.

Mas uma das mais significativas dessas expedições foi a que fez para o Nordeste entre 1928 e 1929, cujos registros transformaram-se numa série de 70 crônicas publicadas no Diário Nacional e, posteriormente, organizadas no livro O Turista Aprendiz. Trata-se do relato do que intitula de "viagem etnográfica", no qual mistura o tom coloquial e poético ao confessional e onde combina suas impressões sobre as danças dramáticas, os mitos, os costumes, a psicologia, a arquitetura, a música, a culinária a outros aspectos culturais dessa região. Nada escapa ao olhar curioso, à reflexão rigorosa e à narração sincera de Mário. Nem mesmo sua arguta denúncia das duras condições sociais e de trabalho do povo nordestino. Ele quer entender o Brasil, mas deixa claro que seu interesse não é ser um folclorista:

Já afirmei que não sou folclorista. $\mathrm{O}$ folclore hoje é uma ciência, dizem... Me interesso pela ciência, porém não tenho capacidade para ser cientista. Minha intenção é fornecer documentação pra músico e não passar vinte anos escrevendo três volumes sobre a expressão fisionômica do lagarto... (Andrade, 1983, p. 232)

Na expedição de 1928, percorreu Alagoas, Pernambuco, Paraíba e Rio Grande do Norte. Em sua passagem pelo Estado potiguar, de todos os deslumbres decorridos, certamente, um dos mais significativos foi o encontro com o cantador de cocos Chico Antônio", na Fazenda Bom Jardim, município de Goianinha: "é um coqueiro muito original na gesticulação e no processo de tirar o coco. Não canta nunca sentado e não gosta de cantar parado" (Andrade, 1983, p. 278).

Para o professor de piano e intelectual paulista custosa era a tarefa de classificar aquele canto sem escala definida, que não estava escrito em partitura. Além disso, aquela música não partia só da garganta do cantor, mas de todo um corpo que dan-

6 Mário não se considerava folclorista e era, antes de tudo, anticientificista.

7 Chico Antônio seria também personagem de seu romance inacabado Café. Apesar do título e do tema, o romance não tem relação com a ópera homônima de que aqui tratamos. 
çava com a voz, de uma vez só. A dificuldade do escritor em encontrar palavras para descrever o que via e ouvia, somada ao desejo de agigantar tudo aquilo com que se identificava, próprio de seu estilo, marcam o tom pungente de seu relato. A apologia alcança a dimensão mística:

Que artista. A voz dele é quente e duma simpatia incomparável. A respiração é tão longa que mesmo depois da embolada inda Chico Antônio sustenta a nota final enquanto o coro entra no refrão. O que faz com o ritmo não se diz! Enquanto os três ganzás, único acompanhamento instrumental que aprecia, se movem interminavelmente no compasso unário, na "pancada do ganzá", Chico Antônio vai fraseando com uma força inventiva incomparável, tais sutilezas certas feitas que a notação erudita nem pense em grafar, se estrepa. E quando tomado pela exaltação musical, o que canta em pleno sonho, não se sabe mais se é música, se é esporte, se heroísmo. Não se perde uma palavra, que nem faz pouco, ajoelhado pro "Boi Tungão", ganzá parado, gesticulando com as mãos doiradas, bem magras, contando a briga que teve com o diabo no inferno, numa embolada sem refrão, durada por 10 minutos sem parar. Sem parar. Olhos lindos, relumeando numa luz que não era do mundo mais. Não era desse mundo mais. (Andrade, 1983, p. 277)

O alumbramento com Chico Antônio é tão grande que Andrade chega a compará-lo ao maior cantor de óperas da época, o tenor italiano Enrico Caruso. De novo, e como sói acontecer com os primeiros etnógrafos brasileiros, a Europa tem de ser usada como referência de qualidade para mesurar algum traço cultural do Brasil - a ópera italiana, nesse caso: "Não sabe que vale uma dúzia de Carusos. Vem da terra, canta por cantar, por uma cachaça, por coisa nenhuma e passa uma noite cantando sem parada" (Andrade, 1983, p. 273).

Em 10 de janeiro de 1929, depois de adentrar a noite ouvindo o coquista da Fazenda Bom Jardim, o escritor lamenta a perspectiva do que o aguarda na capital paulista: "E terei de ir a São Paulo... E terei de escutar as temporadas líricas e as chiques dissonâncias dos modernos..." (Andrade, 1983, p. 277). A lembrança da ópera como expressão artística a que o coco remete sobrevém mais uma vez, desta vez, em desvantagem para o bel canto.

Conforme já apontado por Gilda de Mello e Souza (1979), a utilização das formas de narração popular como expressão literária não era novidade na obra do poeta da Barra Funda. Já o narrador de seu Macunaíma era um cantador, uma espécie de rapsodo que repercute a cultura oral. Se o programa modernista almejava aproximar e conciliar a cultura letrada da cultura oral, o erudito e o popular, Mário teve a oportunidade de experimentar essa operação na redação de sua dramaturgia. A estrutura das variações improvisadas pelas cantigas e cantadores populares perpassa os pregões declinados pelos coros de Café.

Oh gigante da mina do ouro

Oh anões subterrâneos da servidão

Oh magnatas e seus poetas laureados, galões e galinhas [...]

$\mathrm{O}$ vosso peito ladrilhado com pedrinhas diamantes

É concho e vazio feito a bexiga do Mateus (Toni, 2004, p. 223).

Como poeta moderno, Mário é um dos pioneiros, no Brasil, a engendrar em seus poemas a explosão da linguagem. A língua, para ele, reflete a simultaneidade 
de estímulos da experiência na nova vida do contexto urbano e industrial. A partir disso, a sintaxe do povo se apresenta na exploração do valor sonoro das palavras, no ritmo e na melodia dos diferentes sotaques dos personagens-corais, nas aliterações e onomatopeias.

... Plápláplá chiriri côcô pum. Blimblimblim téréréxixi pum. Furrum-fum-fum, furrum-fum-fum. Pipi pipi pipi pipi acaridade pôpô. Porque zunzum zunzum zunzum baile das rosas lero-lero lero-lero lero-lero lero-lero! Cacá cacá cacácacá cacá cá-pum?... Pois tataca teteca titica totoca tutuca!Pum!... Côcô pum!... Xixi pum!... Pipi pum!... Sclá sclá sclá sclásclá sclá sclá sclá dem-dem pum!... pum!... Téréré téréré térérétéréré a grande dama pôpô. Bois sacré railway Tobias Barretopatati lenga-lenga fonfom pum. Sclá sclá sclááa!...Scláááááa!... Sclááááááááááááá-scláááááááááááááa!...Xi!... Xi! (Toni, 2004, p. 219).

A melodia dos falares, diálogos e versos de Café soa, em muitos momentos, como se fosse o canto improvisado de um repentista pernambucano ou de um coquista potiguar. É o caso da Embolada da Ferrugem, entoada pelo personagem Deputadinho da Ferrugem, na primeira cena do ato II:

Sobre a ferrugem/das panelas de cozinha/do país maior mistério/diremos uma cousinha/O assunto é sério/ que as cozinheiras já rugem/coléricas com a ferrugem/das panelas de cozinha/Sobre a cozinha/com ferrugem na panela/Tragédia gloriosa e bela/desta pátria queridinha/Ouvide! Embora/Nossas palavras se sujem/no tremendal da ferrugem/das panelas de cozinha (Toni, 2004, p. 220).

Mário também incorpora na poética de seu libreto as imagens e alegorias das forças da natureza, tão bem exploradas pelos letristas do canto popular. Um dos cocos do repertório de Chico, o Justino Grande, narra o desafio entre Benedito e o forasteiro Justino. Essa letra foi registrada pelo próprio autor paulista, e depois incluída na organização de Oneyda Alvarenga para o livro Os Cocos:

Quando entraram numa sala/Que pegaram a rimá/ Diz que fazia pena/ O Justino vadiá/ Eu me chamo Binidito/ O coqueiro do lugá/Eu sou aquela serpente/ Que você ouviu fala/Faça carreira, Justino/Nós agora vamo dá/ [...] Binidito escavacando/Cum o denende lugá/Era a trigre, era a serpente/ Peito bom prá vadia. (Andrade, 1984, p. 196)

Há muita semelhança entre este trecho com o Coro dos Revolucionários de Café, entoado na cena da Estância de Combate:

É o moço da estrela na testa que vem/Eu disse: ele traz um corisco no pé/É um chefe mais brabo que a tigre ferida/Perverso que nem cascavel/Fatal como enchente do rio. (Toni, 2004, p.230)

A princípio pode parecer estranho que Mário tenha utilizado de elementos de música e literatura oral nordestina para compor uma ópera que se passa entre o porto e as fazendas paulistas. Mas acontece que Café, em que pese o tumultuado contexto em que foi produzida - ainda no embalo das consequências econômicas da crise de 1929, e sua carregada marca de historicidade, vai além dos signos de verossimilhança. $O$ povo que o autor apresenta não é só paulista ou europeu e imigrante. O herói-coletivo de 
sua ópera é, como já vimos, o brasileiro e, até mais, é o povo humilhado do mundo. O discurso de denúncia contra a sujeição do proletariado é internacionalista. Assemelha-se à retórica poética das peças de Bertolt Brecht, Vladimir Maiakovski, Susan Glaspell ou Marc Blitztein ${ }^{8}$. Daí a conotação de parábola marxista da peça, para a qual a premissa dramática transcende tempo e lugar.

Também não há interesse excessivamente realista na ópera. Eram as óperas veristas as que ele mais criticava nas temporadas paulistanas. Trata-se, isso sim, de um enredo linear, de personagens envolvidos em conflitos concretos e de certa conexão entre as cenas e atos que encaminham a fábula para um desfecho. Entretanto, o tom chistoso de paródia que Mário confere a todo o libreto, lhe dá a liberdade de brincar não apenas com a sintaxe, mas também com a composição das personagens, caricatas, quando se trata dos poderosos. Além disso, em relação aos diálogos, não existe preocupação com a lógica do discurso.

Em que pesem as minuciosas descrições de um figurino realista feitas pelo próprio Mário, em termos de texto, a verossimilhança não parece ser uma qualidade relevante. $O$ autor ainda é, antes de tudo, antropofágico. E é dentro dessa licença poética modernista, é pelo assopro de liberdade que o caldeirão cultural de sua ópera intertextual aventa, que Mário arrisca salpicar pregões mato-grossenses, danças dramáticas do Norte, música e poesia oral nordestina. É justamente nessa dimensão antropofágica que as formas poéticas populares brasileiras se amalgamam. É nesse ponto que o coco norteriograndense se encontra com a ópera italiana, é ali que Caruso vira Chico Antônio, que Portinari se torna Chagall, que a denúncia de escravidão dos hebreus de Nabucco grita pela boca dos lavradores de Café.

Portanto, talvez possamos entender o esforço do escritor da pauliceia em colocar o aparato instrumental e a potencialidade sonora de uma orquestra sinfônica e coro lírico a serviço dessa tarefa intertextual. Ou, por outro lado, sua peça também possa ser entendida como um oferecimento da riqueza estética da nossa cultura popular ao gênero operístico.

Claro está ainda a importância da dança para a concepção de sua ópera. No preâmbulo aos originais, denominado Descrição, ele faz uma longa e minuciosa indicação de como imaginava cada elemento da encenação: recursos sonoros, figurinos, adereços, iluminação, cenários e, sobretudo, coreografia. Em texto acerca de seu processo criativo, declarou que a ideia do espetáculo se iniciava mentalmente como "uma coreografia plástica, despreocupado com o realismo, tendendo à formação de visões plásticas" (Levin, 2012, p. 42). Em suas detalhadas rubricas, o libretista extrapola as atribuições meramente dramatúrgicas de sua criação e alcança o rigoroso compêndio de anotações de uma "obra de arte total" de Wagner.

A presença da dança, principalmente a de origem folclórica, unida ao planejamento da coreografia das massas corais, desenha um texto que se aproxima muito mais das danças dramáticas populares, tão caras ao musicólogo, do que dos libretos de ópera convencionais (Toni, 2004). Com todo o conhecimento de pianista e professor de piano, compositor, crítico musical, ouvinte atento de uma vasta discoteca

8 Caberia em outra pesquisa, se é que isso seja possivel, perquirir em que medida Mário, leitor de inglês e alemão, teve contato com a dramaturgia dos autores socialistas de sua época. A semelhança de alguns dos versos de Café com o estilo de Brecht é nítida. 
pessoal de música erudita ${ }^{9}$, espectador das temporadas líricas paulistanas, é possível imaginar que Mário, se quisesse, poderia muito bem ter composto uma ópera nos padrões tradicionais europeus. Seus ensaios a respeito de Literatura também não deixam dúvida acerca de seu conhecimento das formas poéticas canônicas de que os libretistas tradicionais se utilizavam. Elaborasse um libreto convencional e, devido à posição que já ocupava na intelligenzia, certamente teria obtido financiamento e sucesso de público na produção de suas óperas.

De todos os gêneros musicais populares levantados pelo autor, o coco le a embolada) parece ser o que mais vai influenciar a construção da estrutura de sua ópera-coral:

Sob o ponto de vista estritamente musical o coco tem um interesse enorme. Das nossas formas populares é a que tem mais uma importância coral enorme. Se é certo que nas danças dramáticas, bois, maracatus, todos os reisados, congos, o coro entra obrigatoriamente, das formas de música-pura o coco é a única que obriga o coro. E pela variedade com que o coral se manifesta nele se vê que tesouro ele oferece pros nossos compositores desenvolverem não só em música vocal como instrumental também. (Andrade, 1984, p. 364)

Outra característica do coco que encontramos no texto de Café é a disposição das frases de forma a permitir ao compositor que lhe daria a melodia a aceleração crescente no andamento do canto, até o ponto de tornar-se quase uma recitação.

Mário de Andrade era um artista de atitude renascentista, pluriarticulado e de múltiplos engajamentos. Cada obra sua está inserida num programa maior de afirmação de leitura da cultura brasileira. É impossível desvincular sua ópera desse contexto. Do mesmo modo, Mário não era exatamente um libretista. Muito menos dramaturgo. Prova disso é o fato de ter feito três versões de Café e, mesmo assim, considerá-la inacabada. Por isso, é inviável analisar seu texto apenas do ponto de vista dramatúrgico, sem levar em conta as intercorrências da música, de seus estudos de etnomusicologia, Literatura, artes visuais, danças dramáticas e cultura popular que atravessam seu libreto intertextual. Entender sua ópera sem procurar entender nossas danças, cantos e cocos é inconcebível.

\section{Referências}

ANDRADE, Mário. O Turista Aprendiz. São Paulo: Livraria Duas Cidades, 1983.

ANDRADE, Mário. Os cocos. Preparação, introdução e notas de Oneyda Alvarenga. São Paulo/Brasília: Duas Cidades/INL, 1984.

ANDRADE, Mário. Música, Doce Música, São Paulo: Livraria Martins Editora, 1963.

DIGAETANI, John Louis. Convite à Ópera. Rio de Janeiro: Jorge Zahar Ed., 1988. 
LEVIN, Orna Messer. O teatro dos escritores modernistas. In: FARIA, João Roberto (Org.). História do Teatro Brasileiro - vol. 2: Do modernismo às tendências contemporâneas. São Paulo: Perspectiva: Edições SESC/SP, 2013, p. 21- 42.

SATO, Eduardo Tadafumi. Mário de Andrade e a ópera: 2 tempos de crítica (1918-1919 e 1928). In: Anais do XXIV Congresso da Associação Nacional de Pesquisa e Pós-Graduação em Música (ANPPOM), São Paulo, 2014, p. 02-09.

SOUZA, Gilda de Mello e. O tupi e o alaúde: uma interpretação de Macunaíma. São Paulo: Ed. Duas Cidades, 1979.

TONI, Flávia Camargo. Café, uma ópera de Mário de Andrade: estudo e edição anotada. São Paulo, 2004. Tese (Livre-docência), Instituto de Estudos Brasileiros, Universidade de São Paulo.

Recebido em: 28/02/2018 Aprovado em: 30/04/2018 